\title{
Impact of temperature and relative humidity on physicochemical properties of the spray dried red flesh dragon fruit powder during storage
}

\author{
Binh Q. Hoang, Ngoan H. Nguyen, Quan A. Do, Tram N. Pham, \\ Trang L. H. Do, \& Diep T. N. Duong*
}

Faculty of Chemical Engineering and Food Technology, Nong Lam University, Ho Chi Minh City, Vietnam

\author{
ARTICLE INFO \\ Research Paper \\ Received: December 04, 2020 \\ Revised: March 09, 2021 \\ Accepted: March 20, 2021 \\ Keywords \\ Instant powder \\ Red flesh dragon fruit \\ Relative humidity \\ Storage \\ Temperature

\section{${ }^{*}$ Corresponding author} \\ Duong Thi Ngoc Diep \\ Email: duongngocdiep@hcmuaf.edu.vn
}

\begin{abstract}
This study was carried out to evaluate the effects of storage temperature $\left(5-7^{\circ} \mathrm{C}, 29-31^{\circ} \mathrm{C}\right.$, and $\left.50^{\circ} \mathrm{C}\right)$ and relative humidity (RH $10-84 \%$ ) on the stability of antioxidant compounds such as betacyanin, polyphenols. The changes in color, moisture content, the water activity of spray-dried red flesh dragon fruit powder during storage were also observed. The results showed that after 40 days of storage at $5-7^{\circ} \mathrm{C}$, the samples got betacyanin content of $3.76 \mathrm{mg} / 100 \mathrm{~g}$ dw and a total phenolic of $28.31 \mathrm{mg} / 100 \mathrm{~g} \mathrm{dw}$. These values were higher than those of samples stored at ambient temperature $\left(29-31^{\circ} \mathrm{C}\right)$ and $50^{\circ} \mathrm{C}$. Besides, this study also recorded that the low relative humidity of the environment at $10-23 \%$ maintained the product's betacyanin $(4.16-3.61 \mathrm{mg} / 100 \mathrm{~g} \mathrm{dw})$ and polyphenol content $(27.29-25.66 \mathrm{mg} / 100 \mathrm{~g} \mathrm{dw})$ as well as a desirable water activity, which was better than the zone from $57 \%$ to $84 \%(0.28$ $-0.3)$.
\end{abstract}

Cited as: Hoang, B. Q., Nguyen, N. H., Do, Q. A., Pham, T. N., Do, T. L. H., \& Duong, D. T. N. (2021). Impact of temperature and relative humidity on physicochemical properties of the spray dried red flesh dragon fruit powder during storage. The Journal of Agriculture and Development 20(4), 34-42. 


\title{
Ảnh hưởng của độ ẩm tương đối và nhiệt độ đến sự biến đổi thành phần hóa lý của bột thanh long ruột đỏ hòa tan trong quá trình bảo quản
}

\author{
Hoàng Quang Bình, Nguyễn Hồng Ngoan, Đỗ Anh Quân, Phạm Ngọc Trâm, \\ Đỗ Lê Hạnh Trang \& Dương Thị Ngọc Diệp*
}

Khoa Công Nghệ Hóa Học và Thực Phẩm, Trường Đại Học Nông Lâm TP.HCM, TP. Hồ Chí Minh

\author{
THÔNG TIN BÀI BÁO \\ Bài báo khoa học \\ Ngày nhận: 04/12/2020 \\ Ngày chỉnh sửa: 09/03/2021 \\ Ngày chấp nhận: 20/03/2021

\section{Từ khóa} \\ Bảo quản \\ Bột hòa tan \\ Độ ẩm tương đối \\ Niệt độ \\ Thanh long ruột đỏ

\section{*Tác giả liên hệ} \\ Dương Thị Ngọc Diệp \\ Email: duongngocdiep@hcmuaf.edu.vn
}

\section{TÓM TẮT}

Nghiên cứu này đã được thực hiện nhằm đánh giá ảnh hưởng của nhiệt độ bảo quản $\left(5-7^{\circ} \mathrm{C}, 29-31^{\circ} \mathrm{C}\right.$ và $\left.50^{\circ} \mathrm{C}\right)$ và độ ẩm tương đối của môi trường $(\mathrm{RH} 10$ - 84\%) đến sự biến đồi các hợp chất chống oxy hóa như betacyanin, polyphenol cũng như màu sắc, độ ẩm và hoạt độ nước của sản phẩm bột thanh long ruột đỏ trong quá trình bảo quản. Kết quả nghiên cứu cho thấy, sau 40 ngày bảo quản tại nhiệt độ $5-7^{\circ} \mathrm{C}$, mẫu có hàm lượng betacyanin là $3,76 \mathrm{mg} / 100 \mathrm{~g}$ vật chất khô (vck) và polyphenol tổng là $28,31 \mathrm{mg} / 100 \mathrm{~g}$ vck; các giá trị này cao hơn so với mẫu được bảo quản tại nhiệt độ môi trường $\left(29-31^{\circ} \mathrm{C}\right)$ và $50^{\circ} \mathrm{C}$. Bên cạnh đó, kết quả nghiên cứu cũng đã ghi nhận được độ ẩm môi trường từ $10 \%-23 \%$ cho sản phẩm có hàm lượng betacyanin $(4,16-3,61 \mathrm{mg} / 100 \mathrm{~g} \mathrm{vck})$ và polyphenol tổng (27,29 - 25,66 mg/100 g vck), cũng như hoạt độ nước độ nước $(0,28$ - 0,3) tốt hơn so với vùng độ ẩm $57-84 \%$.

\section{1. Đặt Vấn Đề}

Thanh long ruột đỏ đã được xác định là nguồn nguyên liệu có chứa betacyanin $(10,3 \pm 0,22$ $\mathrm{mg} / 100 \mathrm{~g}$ thịt quả và $13,8 \pm 0,85 \mathrm{mg} / 100$ vỏ quả) và polyphenol $(42,4 \pm 0,04 \mathrm{mg} \mathrm{GAE} / 100 \mathrm{~g}$ thịt quả và $39,7 \pm 5,39 \mathrm{mg} \mathrm{GAE} / 100 \mathrm{~g}$ vỏ quả), là những chất chống oxy hóa có lợi cho sức khỏe (Wu \& ctv., 2006). Tại Việt Nam, thanh long được trồng với số lượng lớn; tuy nhiên, thanh long chỉ mới được tiêu thụ ở dạng ăn tươi, chỉ một số ít sản phẩm được chế biến theo quy mô công nghiệp. Trong thập kỉ gần đây, tình trạng được mùa mất giá thường xuyên xảy ra đối với thanh long. Do đó, chế biến các sản phẩm từ thanh long ruột đỏ là điều cần thiết. Trong các nghiên cứu trước đó, thanh long ruột đỏ đã được chế biến thành bột hòa tan (Tze \& ctv., 2012; Bakar \& ctv., 2013). Tuy nhiên, các tác giả này hiện chỉ mới tập trung đánh giá ảnh hưởng của điều kiện sấy như nhiệt độ sấy, chất trợ sấy đến chất lượng của bột thanh long. Trong khi đó, thông tin về sự biến đổi thành phần hóa lý, màu sắc của bột thanh long trong quá trình bão quản vẫn bị hạn chế; điều này gây khó khăn cho ứng dụng thực tiễn bột thanh long trong sản xuất thực tế.

Các nghiên cứu về bột trái cây như trái mãng cầu (Chang \& ctv., 2018), bột trái gấc (Kha \& ctv., 2015), bột trái mâm xôi đen (Ferrari \& ctv., 2013) đã cho thấy độ ẩm môi trường và nhiệt độ bảo quản là một trong những yếu tố ảnh hưởng lớn đến sự ổn định các đặc tính hóa lý, cũng như các hợp chất kháng oxy của bột trái cây trong quá trình bảo quản. Nghiên cứu này đã được thực hiện nhằm đánh giá các ảnh hưởng của độ ẩm môi trường cũng như nhiệt độ đến sự ổn định của hợp chất polyphenol, betacyanin, hoạt độ nước và màu sắc của sản phẩm bột thanh long ruột đỏ hòa tan trong quá trình bảo quản. 


\section{Vật Liệu và Phương Pháp Nghiên Cứu}

\subsection{Nguyên liệu và hóa chất}

Nguyên liệu: Đối tượng nghiên cứu chính của đề tài là thanh long ruột đỏ được mua từ chợ đầu mối nông sản Thủ Đức, TP.HCM, có xuất xứ từ nhà vườn tỉnh Bình Thuận. Những trái còn tươi, không bị giập nát và không có dấu hiệu các đốm nấm được lựa chọn. Nguyên liệu thanh long được sơ chế, cắt bỏ tai và vỏ lụa bên ngoài; tách lấy phần vỏ và thịt quả. Các nguyên liệu này được bảo quản ở $-18^{\circ} \mathrm{C}$.

Hóa chất: $\mathrm{NaOH} \geq 96 \%, \mathrm{Na}_{2} \mathrm{CO}_{3} \geq 99,8 \%$, thiourea $\geq 99 \%$, axit metaphosphoric $\geq 38 \%$, axit acetic 99,5\%, bromie $3 \%$, sulfuric acid 95 98\% (Xilong, Trung Quốc); 2,4 - dinitrophenylhydrazine $(\mathrm{DPPH}) \geq 99,9 \%$, Folin - Ciocalteu 99,5\% (Merck, Đức); axit gallic (99\%, Nhật Bản); axit ascorbic chuẩn ( $\geq 99,98 \%$, Ân Độ).

\subsection{Chuẩn bị mẫu}

Chuẩn bị dịch quả: Nguyên liệu (đã chuẩn bị mục 2.1) được rã đông tại nhiệt độ phòng. Phần thịt quả sau khi ép bằng máy ép (Electrolux ESJ4000S, Thụy Điển), dịch ép được phối trộn cùng với nước theo tỷ lệ 1:1 $(\mathrm{g} / \mathrm{g})$. Hỗn hợp được thủy phân với xúc tác của enzyme Pectinex Ultra SP-L có tỷ lệ bổ sung là $0,2 \%$, nhiệt độ $45^{\circ} \mathrm{C}$ trong 60 phút. Sau đó, hỗn hợp được lọc thu dịch. Phần vỏ được xay bằng máy xay (Philips HR2118, Hà Lan) với nước theo tî̉ lệ 1:1 (g/g). Hỗn hợp được thủy phân với xúc tác của enzyme Pectinex Ultra SP-L có tỷ lệ bổ sung là $0,2 \%$, nhiệt độ $45^{\circ} \mathrm{C}$ trong 90 phút. Sau đó hỗn hợp được lọc thu hồi dịch.

Sấy phun: Dịch thịt quả và dịch vỏ quả được phối trộn theo tỷ lệ 4:1 (g/g). Hỗn hợp sau đó được bổ sung maltodextrin đến khi đạt nồng độ $15 \%(\mathrm{~g} / \mathrm{g})$, sau đó mẫu được đồng hóa tại 5000 vòng/phút trong 5 phút. Quá trình sấy phun được thực hiện ở chế độ tốc độ dòng nhập liệu 500 $\mathrm{mL} / \mathrm{h}$, tốc độ quay của bơm là 2,5 vòng/phút và áp suất khí nén là $2,1 \mathrm{~kg} / \mathrm{cm}^{2}$, với nhiệt độ đầu vào là $150^{\circ} \mathrm{C}$. Mẫu sau đó được bảo quản trong túi polyamide tráng nhôm (dày $0,16 \pm 0,02 \mathrm{~mm}$ ) ghép mí, ở nhiệt độ $<-18^{\circ} \mathrm{C}$ cho đến khi các thí nghiệm của nghiên cứu được thực hiện.

Phối trộn công thức: Bột thanh long được lấy ra khỏi tủ đông và nâng nhiệt độ bằng cách để ở nhiệt độ phòng. Khi đạt nhiệt độ phòng, bột được phối trộn cùng đường saccharose và axit citric theo tỷ lệ 1:12:0,35 (g/g/g). Mẫu bột đã phối trộn được sử dụng trong ngày để thực hiện các thí nghiệm khảo sát trong nghiên cứu.

Các thông số được áp dụng trong quy trình chuẩn bị mẫu là kết quả đã được thực hiện trong nghiên cứu trước đó của nhóm tác giả.

\section{3. Ảnh hưởng của nhiệt độ đến biến đổi thành phần hóa lý của bột thanh long ruột đỏ}

Ở thí nghiệm này, $10 \mathrm{~g}$ bột (đã chuẩn bị trong mục 2.2) được đặt vào trong bao polyamide tráng nhôm có độ dày $0,16 \pm 0,02 \mathrm{~mm}$, ghép mí để tiến hành bảo quản ở ba nhiệt độ khác nhau $5^{\circ} \mathrm{C} \pm$ 1 (ngăn mát tủ lạnh), $30^{\circ} \mathrm{C} \pm 1$ (điều kiện môi trường) và $50^{\circ} \mathrm{C}$ (tủ ủ). Tính từ thời điểm bắt đầu bảo quản, sau $5,10,15,20,30$ và 40 ngày, mẫu được phân tích hàm lượng betacyanin, hàm lượng polyphenol tổng, độ ẩm, hoạt độ nước, L* $a^{*} b^{*}$.

\section{4. Ảnh hưởng độ ẩm tương đối của môi trường bảo quản đến biến thành phần hóa lý của bột thanh long ruột đỏ}

Phương pháp thực hiện được tham khảo Greenspan (1997). Cân $2 \mathrm{~g}$ bột (đã chuẩn bị trong mục 2.2) bằng cân kỹ thuật (AND, Fx-1200i, Nhật Bản) vào trong túi zipper nhựa polyethylene (có kích thước $4 \mathrm{~cm} \times 6 \mathrm{~cm}$, độ dày $0,1 \pm$ 0,01 mm), miệng bao được để hở, không ghép mí giúp đẩy nhanh quá trình cân bằng ẩm của mẫu. Lần lượt cho mỗi cốc thủy tinh $100 \mathrm{~mL}$ có chứa các dung dịch bão hòa của $\mathrm{NaOH}, \mathrm{CH}_{3} \mathrm{COOK}$, $\mathrm{Mg}\left(\mathrm{NO}_{3}\right)_{2}, \mathrm{NaCl}$ và $\mathrm{KCl}$ vào các bình hút ẩm. Bình hút ẩm được để ổn định trong 24 giờ để tạo các môi trường có độ ẩm tương đối $(\mathrm{RH})$ lần lượt là $10 \%, 23 \%, 57 \%, 76 \%$ và $84 \%$. Tiếp theo mẫu được cho vào bình hút ẩm và bảo quản trong 14 ngày tại nhiệt độ phòng $29-31^{\circ} \mathrm{C}$. Sau khi bảo quản, mẫu bột thanh long được phân tích hoạt độ nước, độ ẩm, hàm lượng betacyanin, hàm lượng polyphenol tổng.

\subsection{Phương pháp phân tích}

\subsubsection{Xác định độ ẩm}

Hàm lượng ẩm được xác định bằng máy đo ẩm hồng ngoại (AND, MX-50, Nhật Bản). 


\subsubsection{Xác định hoạt độ nước $\left(\mathrm{a}_{\mathrm{w}}\right)$}

Mẫu thí nghiệm được xác định bằng máy đo hoạt độ nước (Aqua Lab 3, Decagon Devices, Mỹ).

\subsubsection{Phân tích màu sắc $\mathrm{L}^{*} \mathrm{a}^{*} \mathrm{~b}^{*}$}

Mẫu được xác định bằng máy đo màu (Chroma meter CR400, Nhật Bản). Công thức xác định cường độ màu (Chroma) và sự khác biệt màu sắc $(\Delta \mathrm{E})$ được tham chiếu theo (Kha \& ctv., 2015), trong đó:

Cường độ màu sắc (Chroma) được tính theo công thức $\sqrt{\mathrm{a}^{*^{2}}+\mathrm{b}^{*^{2}}}$

Sự khác biệt màu sắc:

$\Delta \mathrm{E}=\sqrt{\left(\mathrm{L}_{0}^{*}-\mathrm{L}^{*}\right)^{2}+\left(\mathrm{a}_{0}^{*}-\mathrm{a}^{*}\right)^{2}+\left(\mathrm{b}_{0}^{*}-\mathrm{b}^{*}\right)^{2}}$, trong đó: $\mathrm{L}_{0}^{*}, \mathrm{a}_{0}^{*}, \mathrm{~b}_{0}^{*}$ giá trị của của mẫu trước bảo quản và $L^{*}, a^{*}, b^{*}$ là giá trị đo được của mỗi mẫu tại thời điểm phân tích.

\subsubsection{Xác định hàm lượng betacyanin}

Phương pháp phân tích được tham khảo Ee \& ctv. (2014). Cân $1 \mathrm{~g}$ bột bằng cân kỹ thuật (AND, Fx-1200i, Nhật Bản), bột được lắc đều cùng với $25 \mathrm{~g}$ nước cất. Sau đó mẫu được ly tâm (Z206 A, Hermle Labortechnik, Đức) với tốc độ 5000 vòng/phút trong 10 phút. Dịch ly tâm được lọc qua giấy lọc (New start, Trung Quốc). Sau đó, mẫu được đem đi đo ở bước sóng $538 \mathrm{~nm}$ (Genesis, Thermo Scientific, Mỹ) (Ee \& ctv., 2014). Hàm lượng betacyanin được tính theo công thức $\mathrm{BC}(\mathrm{mg} / 100 \mathrm{~g} \mathrm{vck})=\frac{\mathrm{A} \times \mathrm{M} \times \mathrm{V} \times \mathrm{F} \times 100}{\varepsilon \times \mathrm{L} \times \mathrm{W}}$. Trong đó: $\mathrm{BC}$ là nồng độ betacyanin; $\mathrm{A}$ là giá trị hấp thụ ở mức hấp thụ tối đa $(\lambda \max =538 \mathrm{~nm})$; $\mathrm{F}$ là hệ số pha loãng, $\mathrm{M}$ là trọng lượng phân tử của betanin $(550 \mathrm{~g} / \mathrm{moL}) ; \varepsilon$ là hệ số mol tuyệt đối của betanin ( $\varepsilon=600001 / \mathrm{moL} . c m$ trong nước); $\mathrm{L}$ là chiều dài của cuvet $(\mathrm{L}=1 \mathrm{~cm}) ; \mathrm{V}$ là thể tích dịch chiết $(\mathrm{mL})$; W là khối lượng mẫu cân tính theo vật chất khô (vck) (g).

\subsubsection{Xác định hàm lượng polyphenol}

Phương pháp được tham chiếu theo Singleton \& ctv., (1999) và Huynh \& ctv. (2014). Trong một ống nghiệm, lắc đều hỗn hợp gồm $1 \mathrm{~mL}$ nước cất, $1 \mathrm{~mL}$ mẫu đã được pha loãng và $0,5 \mathrm{~mL}$ Follin $10 \%$. Sau 6 phút, tiếp tục thêm $1,5 \mathrm{~mL} \mathrm{Na} 2 \mathrm{CO}_{3}$ $20 \%$ và $1 \mathrm{~mL}$ nước cất, lắc đều. Sau 2 giờ, mẫu được phân tích đo mật độ quang ở bước sóng 760 nm. Hàm lượng polyphenol tổng của mẫu được thể hiện là mg GAE/100 g vck.

Sự suy giảm của betacyanin và polyphenol được tính theo công thức: $\ln (\mathrm{C})-\ln \left(\mathrm{C}_{\mathrm{o}}\right)=-\mathrm{kt}$. Trong đó, $\mathrm{C}$ là hàm lượng betacyanin/polyphenol của mẫu trước bảo quản, $\mathrm{C}_{\mathrm{o}}$ là hàm lượng betacyanin/polyphenol sau thời gian bảo quản tại thời điểm $\mathrm{t}, \mathrm{k}$ là hằng số độ phản ứng.

\subsection{Phương pháp xử lý số liệu}

Các kết quả thể hiện là giá trị trung bình \pm độ lệch chuẩn. Các thí nghiệm được thực hiện 3 lần lặp lại. Các số liệu thu thập được xử lý và vẽ đồ thị bằng phần mền Excel 2010, phương pháp phân tích phương sai (ANOVA) với $\alpha=0,05$ và phần mềm JMP 10 được sử dụng để phân tích sự khác biệt giữa các mẫu thí nghiệm.

\section{Kết Quả và Thảo Luận}

\section{1. Ảnh hưởng của nhiệt độ bảo quản đến biến đổi thành phần hóa lý của bột thanh long ruột đỏ}

Nhiệt độ bảo quản đã ảnh hưởng đến sự ổn định của các hợp chất chống oxy hóa có trong bột thanh long ruột đỏ. Sau 40 ngày bảo quản, cả hai hợp chất betacyanin và polyphenol đều giảm so với trước bảo quản (Bảng 1). Mẫu được bảo quản tại nhiệt độ $5^{\circ} \mathrm{C}$ có tốc độ suy giảm betacyanin (từ 4,35 xuống $3,75 \mathrm{mg} / 100 \mathrm{~g}$ vck) và polyphenol (từ 31,82 xuống $28,31 \mathrm{mg} / 100 \mathrm{~g}$ vck) chậm hơn so với mẫu bảo quản tại nhiệt độ $29-31^{\circ} \mathrm{C}$ (betacyanin giảm từ 4,31 xuống 2,91 $\mathrm{mg} / 100 \mathrm{~g}$ vck và polyphenol giảm từ 31,82 xuống $27,37 \mathrm{mg} / 100 \mathrm{~g}$ vck) và $50^{\circ} \mathrm{C}$ (betacyanin giảm từ 4,31 xuống $2,73 \mathrm{mg} / 100 \mathrm{~g}$ vck và polyphenol giảm từ 31,82 xuống $20,53 \mathrm{mg} / 100 \mathrm{~g}$ vck). Kết quả Bảng 2 cho thấy, sự suy giảm của betacyanin và polyphenol phụ thuộc vào nhiệt độ, mối quan hệ này được thể hiện theo phương trình bậc 1 , với giá trị $R^{2}>0,93$ (betacyanin), và $R^{2}>0,90$ (polyphenol). Kết quả này cũng thống nhất với nghiên cứu của Ee \& ctv. (2014) và Herbach \& ctv. (2004), các tác giả này cũng đã phát hiện sự suy giảm của betacyanin có trong dịch ép hoặc bột vỏ thanh long trong quá trình xử lý nhiệt tuân theo phương trình bậc 1 . Dấu (-) xuất hiện trước hệ số góc trong các phương trình cho thấy mối tương quan nghịch giữa các yếu tố khảo sát. Ngoài ra Bảng 2 cũng cho thấy hằng số tốc độ suy thoái của betacyanin tăng từ 0,0035 đến 0,007 và 


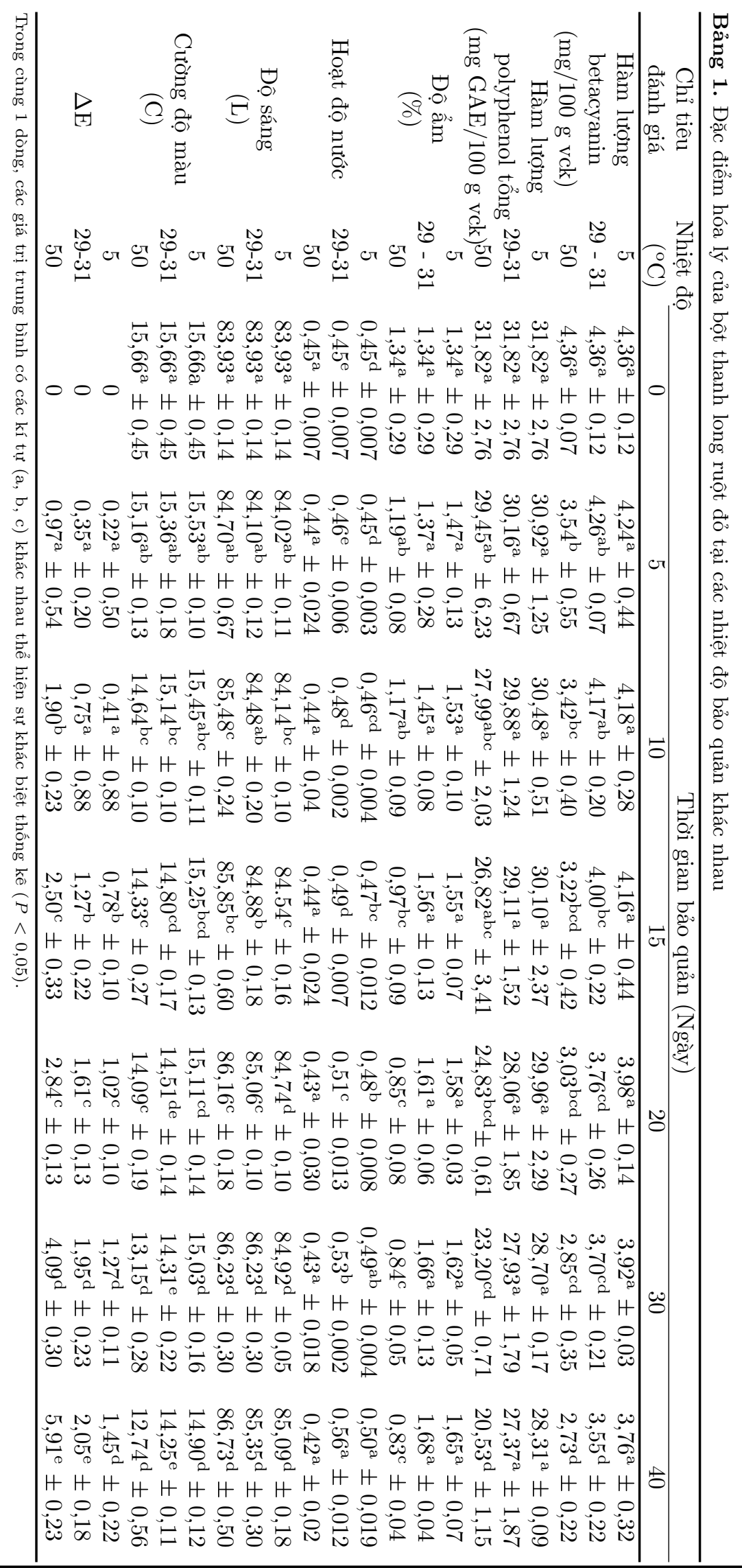


Bảng 2. Hằng số tốc độ suy thoái hàm lượng betacyanin của bột thanh long ở điều kiện bảo quản khác nhau

\begin{tabular}{clccl}
\hline Nhiệt độ bảo quản $\left({ }^{\circ} \mathrm{C}\right)$ & $\begin{array}{c}\text { Hằng số tốc độ suy } \\
\text { thoái } \mathrm{k}\left(\mathrm{ngày}^{-1}\right)\end{array}$ & Hệ số tương quan $\left(\mathrm{R}^{2}\right)$ & Phương trình \\
\hline Betacyanin & 5 & 0,0035 & 0,96 & $\mathrm{y}=-0,0035 \mathrm{x}-0,0079$ \\
& 50 & 0,0053 & 0,93 & $\mathrm{y}=-0,0053 \mathrm{x}-0,0054$ \\
& 50 & 0,0077 & 0,98 & $\mathrm{y}=-0,0077 \mathrm{x}-0,176$ \\
Polyphenol & & & \\
& 5 & 0,0026 & 0,97 & $\mathrm{y}=-0,0026 \mathrm{x}-0,0153$ \\
& 30 & 0,0029 & 0,90 & $\mathrm{y}=-0,0029 \mathrm{x}-0,0445$ \\
& 50 & 0,0069 & 0,96 & $\mathrm{y}=-0,0069 \mathrm{x}-0,0331$ \\
\hline
\end{tabular}

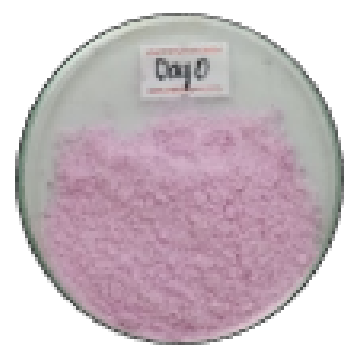

A

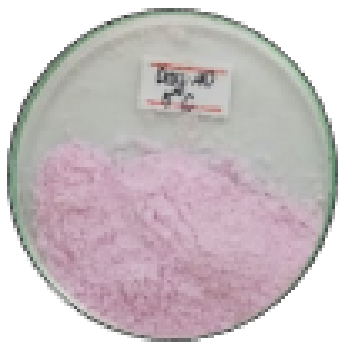

$\mathrm{B}$

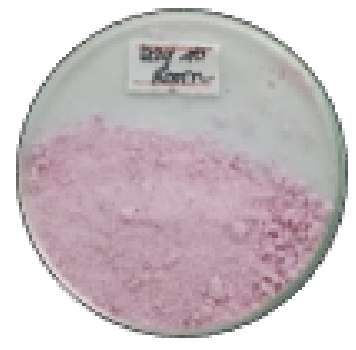

C

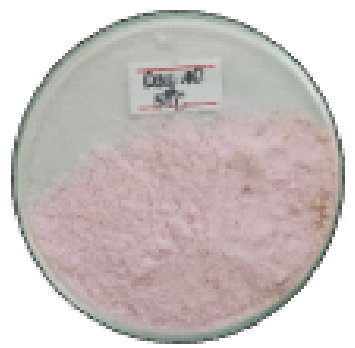

$\mathrm{D}$

Hình 1. Màu sắc của bột thanh long $(\mathrm{A})$ Trước bảo quản và sau 40 ngày bảo quản tại các nhiệt độ khác nhau (B) $5-7^{\circ} \mathrm{C}$; (C) Nhiệt độ phòng, (C) $50^{\circ} \mathrm{C}$.

polyphenol tăng từ 0,0026 đến 0,0069 khi tăng nhiệt độ bảo quản từ $5^{\circ} \mathrm{C}$ đến $50^{\circ} \mathrm{C}$.

Betacyanin và polyphenol là những chất nhạy cảm với nhiệt độ, đây là nguyên nhân giải thích cho sự suy giảm mạnh của các hợp chất này tại nhiệt độ cao.

Nhìn chung, bột thanh long được bảo quản ở cả nhiệt độ phòng và nhiệt độ $5-7^{\circ} \mathrm{C}$ không có sự khác biệt nhiều về hàm lượng betacyanin cũng như polyphenol. Điều này có thể do, trong quá trình sấy phun, maltodextrin đã vi bao các hợp chất kháng oxy hóa, trở thành màng chắn bảo vệ các hợp này dưới tác động của nhiệt độ môi trường, đồng thời hai nhiệt độ được khảo sát không quá cao, ít tác động đến quá trình suy giảm hợp chất kháng oxy hóa. Trong nhiều nghiên cứu trước đó về bảo quản bột trái chùm ruột (Hernández-Sandoval \& ctv., 2014), trái ổi (Shishir \& ctv., 2017), trái thanh mai (Fang \& Bhandari, 2011) cũng đã cho thấy nhiệt độ thấp giúp duy trì tốt hợp chất kháng oxy hóa có trong các mẫu bột trái cây sấy phun.

Hoạt độ nước, độ ẩm, độ sáng và $\Delta \mathrm{E}$ của mẫu tăng dần theo thời gian bảo quản, ngược lại cường độ màu giảm dần. Sau 40 ngày, không có sự khác biệt đáng kể về hoạt độ nước $(0,50$ - 0,56), độ ẩm $(1,65 \%-1,68 \%)$, độ sáng $L(85,09$ và 85,35$)$ và cường độ màu $(14,90$ và 14,35$)$ giữa các mẫu bảo quản tại nhiệt độ $5^{\circ} \mathrm{C}$ và $29-31^{\circ} \mathrm{C}$. Tuy nhiên giữa các mẫu này lại có sự khác biệt rõ về $\Delta \mathrm{E}$, giá trị ghi nhận được lần lượt là $1,45\left(5^{\circ} \mathrm{C}\right)$ và $2,05\left(29-31^{\circ} \mathrm{C}\right)$ sau 40 ngày bảo quản. Lúc này, mẫu bảo quản vẫn duy trì được màu hồng so với mẫu ban đầu, tuy nhiên cường độ màu đã nhạt dần (Hình 1). Nhìn chung, tùy theo mục đích sử dụng mà nhà sản xuất có thể lựa chọn nhiệt độ bảo quản thích thích hợp, nhiệt độ thấp $\left(5^{\circ} \mathrm{C}\right)$ giúp duy trì tốt chất lượng sản phẩm, trong khi đó nhiệt độ phòng giúp giảm chi phí phân phối, bảo quản và giá thành sản phẩm. Trong nghiên cứu này, nhiệt độ môi trường được lựa chọn là thông số cố định cho thí nghiệm tiếp theo.

\section{2. Ảnh hưởng độ ẩm của môi trường bảo quản đến biến thành phần hóa lý của bột thanh long ruột đỏ}

Độ ẩm môi trường bảo quản càng tăng đã làm giảm hàm lượng betacyanin và polyphenol tổng có trong bột thanh long (Bảng 3). Sau 14 ngày, mẫu có hàm lượng betacyanin cao nhất là 4,16 


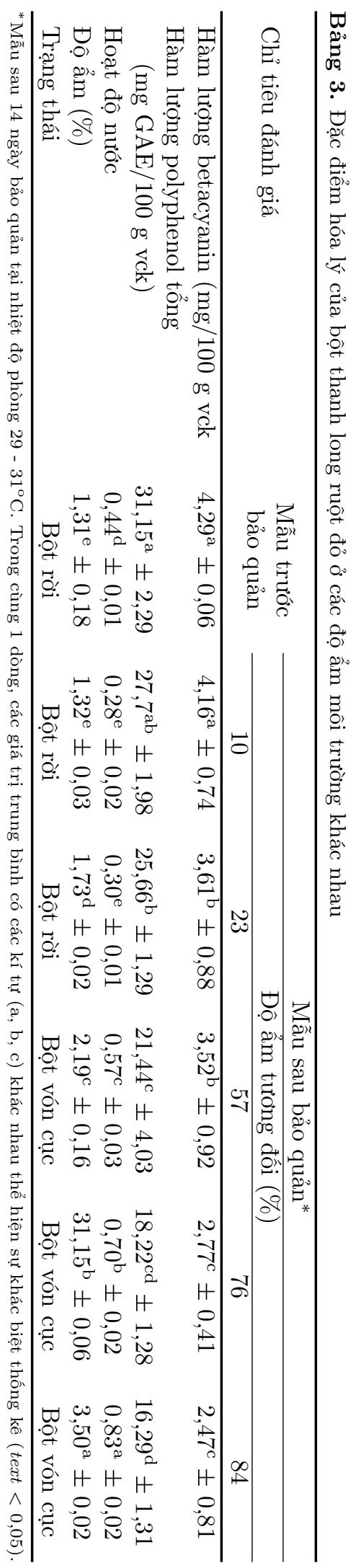

mg/100 g vck tại RH $10 \%$ và thấp nhất là 2,47 $\mathrm{mg} / 100 \mathrm{~g}$ vck tại RH 84\%. Tại các độ ẩm này, thí nghiệm cũng đã ghi nhận được hàm lượng polyphenol tổng cao nhất và thấp nhất tương ứng lần lượt là $27,79 \mathrm{mg} / 100 \mathrm{~g}$ vck và $16,29 \mathrm{mg} / 100 \mathrm{~g}$ vck. Kết quả này cũng tương đồng với nghiên cứu của Fang \& Bhandari (2011); hàm lượng polyphenol trong bột trái thanh mai giảm khi ẩm độ môi trường tăng.

Hoạt độ nước và độ ẩm của mẫu càng tăng khi độ ẩm của môi trường bảo quản càng tăng. Độ ẩm môi trường bảo quản tăng từ $10 \%$ đến $84 \%$ đã dẫn đến độ ẩm của mẫu tăng từ $0,28 \%$ đến $0,83 \%$ và hoạt độ nước tăng từ $1,32 \%$ và $3,50 \%$. Như vậy, độ ẩm môi trường có sự tương quan thuận với hoạt độ nước $\left(\mathrm{R}^{2}=0,98\right)$ và độ ẩm $\left(\mathrm{R}^{2}=0,97\right)$ của sản phẩm bột thanh long. Trong nghiên cứu trước đó về bột trái cây sản xuất bằng phương pháp sấy phun cũng đã cho thấy, độ ẩm môi trường bảo quản và độ ẩm, hoạt độ nước của sản phẩm có mối tương quan thuận (Fang \& Bhandari, 2011; Badii \& ctv., 2014; Kha \& ctv., 2015).

Như vậy, có hai xu hướng ghi nhận được trong thí nghiệm này, độ ẩm và hoạt độ nước của mẫu tăng theo chiều tăng độ ẩm của môi trường; ngược lại hàm lượng betacyanin và polyphenol trong mẫu giảm theo chiều tăng độ ẩm môi trường. Nói cách khác, giữa hoạt độ nước và hàm lượng betacyanin và polyphenol có mối tương quan nghịch, với hệ số tương quan lần lượt là $\mathrm{R}^{2}=0,99$ và $\mathrm{R}^{2}=0,97$.

Gia tăng hàm lượng nước trong sản phẩm có thể làm giảm nhiệt độ hóa gương của sản phẩm (Bhandari \& ctv., 1997). Do đó, sản phẩm sấy khô cần được bảo quản tại nhiệt độ thấp hơn so với nhiệt độ $\mathrm{T}_{\mathrm{g}}$ của nó. Trong nghiên cứu của Chang \& ctv. (2018), Fang \& Bhandari (2011) đã đưa ra các minh chứng cho thấy, sự gia tăng hàm lượng ẩm đã làm giảm giá trị $\mathrm{T}_{\mathrm{g}}$ của bột mãng cầu, bột trái thanh mai; điều này dẫn đến sự gia tăng tỷ lệ thất thoát polyphenol và biến đồi màu sắc của sản phẩm. Đây có thể là nguyên nhân giúp giải thích sự suy giảm của betacyanin, polyphenol trong bột thanh long tại RH 76 - 84\% nhanh hơn so với các mẫu còn lại.

Bên cạnh đó, sự gia tăng hàm lượng nước có thể đã thúc đẩy phản ứng oxy hóa làm suy giảm hảm lượng các hợp chất kháng oxy hóa này. Hiện tượng này cũng đã được đề cập trong nghiên cứu của Mba \& ctv. (2019), nhóm tác giả đã phát hiện sự gia tăng hàm lượng nước trong quá trình 


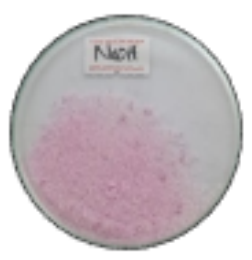

A

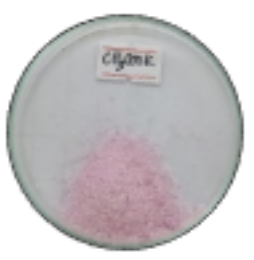

B

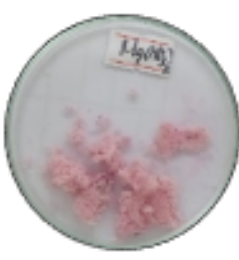

C

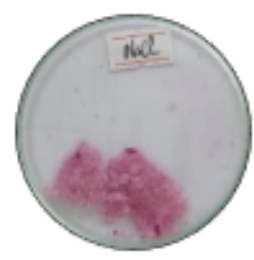

$\mathrm{D}$

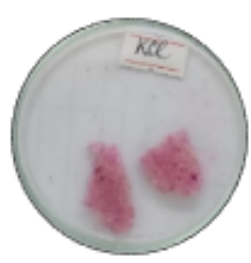

$\mathrm{E}$

Hình 2. Hình ảnh bột thanh long sau 14 ngày bảo quản ở nhiệt độ phòng tại các độ ẩm tương đối khác nhau (A): 10\%, (B): 23\%, (C): 57\%, (D): $76 \%$, (E): $84 \%$.

ngâm đậu có tương quan thuận $\left(\mathrm{R}^{2}>0,85\right)$ với sự gia tăng tỷ lệ thất thoát polyphenol. Một nguyên nhân khác có thể dẫn đến sự suy giảm polyphenol là do hoạt động thủy phân của enzyme polyphenol oxidase và peroxidase; hai loại enzyme này đã được phát hiện tồn tại trong thịt quả thanh long theo nghiên cứu của Santos \& ctv. (2020).

Ngoài ra, độ ẩm tương đối của môi trường đã có ảnh hưởng đến đặc tính cảm quan của mẫu. Môi trường có RH > 57\% các mẫu có hiện tượng vón cục; màu hồng sáng; ngược lại, $\mathrm{RH}<57 \%$ các mẫu không vón cục và có màu hồng phấn (Hình 2). Maltodextrin là vật liệu dễ hút ẩm, do đó trong môi trường có độ ẩm tương đối cao, bột thanh long dễ bị hút ẩm làm mẫu vón cục. Môi trường $\mathrm{RH}<57 \%$ giúp duy trì tốt hàm lượng các chất kháng oxy hóa, màu sắc, độ ẩm và hoạt độ nước của bột thanh long.

\section{Kết Luận}

Hàm lượng betacyanin, polyphenol và hoạt độ nước, độ ẩm, màu sắc của bột thanh long ruột đỏ chịu tác động của nhiệt độ và độ ẩm môi trường bảo quản. Nhiệt độ thấp $\left(5^{\circ} \mathrm{C}\right)$ hoặc độ ẩm môi trường thấp $(\mathrm{RH}<57 \%)$ giúp lưu giữ tốt hàm lượng các chất kháng oxy hóa như betacyanin, polyphenol cũng như độ ẩm, màu sắc, hoạt độ nước của bột thanh long ruột đỏ.

\section{Tài Liệu Tham Khảo (References)}

Badii, F., Farahnaky, A., \& Behmadi, H. (2014). Effect of storage relative humidity on physical stability of dried fig. Journal of Food Processing and Preservation $38(1), 477-483$.

Bakar, J., Ee, S. C., Muhammad, K., Hashim, D. M., \& Adzahan, N. (2013). Spray-drying optimization for red pitaya peel (Hylocereus polyrhizus). Food and Bioprocess Technology 6(5), 1332-1342.

Bhandari, B. R., Datta, N., Crooks, R., Howes, T., \& Rigby, S. (1997). A semi-empirical approach to opti- mise the quantity of drying aids required to spray dry sugar rich foods. Drying Technology 15(10), 2509-2525.

Chang, L. S., Karim, R., Abdulkarim, S. M., Yusof, Y. A., \& Ghazali, H. M. (2018). Storage stability, color kinetics and morphology of spray-dried soursop ( $A n$ nona muricata L.) powder: effect of anticaking agents. International Journal of Food Properties 21(1), 19371954.

Ee, S. C., Bakar, J., Kharidah, M., Dzulkifly, M. H., \& Noranizan, A. (2014). Physico-chemical properties of spray-dried red pitaya (Hylocereus polyrhizus) peel powder during storage. International Food Research Journal 21(1), 155-160.

Fang, Z., \& Bhandari, B. (2011). Effect of spray drying and storage on the stability of bayberry polyphenols. Food Chemistry 129(3), 1139-1147.

Ferrari, C. C., Germer, S. P. M, Alvim, I. D., \& de Aguirre, J. M. (2013). Storage stability of spray-dried blackberry powder produced with maltodextrin or gum arabic. Drying Technology 31(4), 470-478.

Greenspan, L. (1977). Humidity fixed points of binary saturated aqueous solution. Journal of Research of the National Bureau of Standards-A. Physics and Chemistry 81(1), 89-96.

Herbach, K. M., Stintzing, F. C., \& Carle, R. (2004). Thermal degradation of betacyanins in juices from purple pitaya [Hylocereus polyrhizus (Weber) Britton \& Rose] monitored by high-performance liquid chromatography-tandem mass spectometric analyses. European Food Research and Technology 219(4), 377-385.

Hernández-Sandoval, G. R., Cortés-Rodríguez, M., \& Ciro-Velásquez, H. J. (2014). Effect of storage conditions on quality of a functional powder of cape gooseberry obtained by spray drying. Revista UDCA Actualidad \& Divulgación Científica 17(1), 139-149.

Huynh, N. T., Smagghe, G., Gonzales, G. B., Van Camp, J., \& Raes, K. (2014). Enzyme-assisted extraction enhancing the phenolic release from cauliflower (Brassica oleracea L. var. botrytis) outer leaves. Journal of Agricultural and Food Chemistry 62(30), 7468-7476.

Kha, T. C., Nguyen, M. H., Roach, P. D., \& Stathopoulos, C. E. (2015). A storage study of encapsulated gac (Momordica cochinchinensis) oil powder and its fortification into foods. Food and Bioproducts Processing 96, 113-125. 
Mba, O. I., Kwofie, E. M., \& Ngadi, M. (2019). Kinetic modelling of polyphenol degradation during common beans soaking and cooking. Heliyon 5(5), e01613.

Santos, G. B. M., Dionísio, A. P., Magalhães, H. C. R., de Abreu, F. A. P., Lira, S. M., de Lima, A. C. V., ... \& Zocolo, G. J. (2020). Effects of processing on the chemical, physicochemical, enzymatic, and volatile metabolic composition of pitaya (Hylocereus polyrhizus (F.A.C. Weber) Britton \& Rose). Food Research International 127, 108710.

Shishir, M. R. I., Taip, F. S., Saifullah, M., Aziz, N. A., \& Talib, R. A. (2017). Effect of packaging materials and storage temperature on the retention of physicochemical properties of vacuum packed pink guava powder. Food Packaging and Shelf Life 12, 83-90.
Tze, N. L., Han, C. P., Yusof, Y. A., Ling, C. N., Talib, R. A., Taip, F. S., \& Aziz, M. G. (2012). Physicochemical and nutritional properties of spray-dried pitaya fruit powder as natural colorant. Food Science and Biotechnology 21(3), 675-682.

Wu, L. C., Hsu, H. W., Chen, Y. C., Chiu, C. C., Lin, Y. I., \& Ho, J. A. A. (2006). Antioxidant and antiproliferative activities of red pitaya. Food Chemistry 95(2), 319-327. 